\title{
Macroscopic Findings Body System
}

National Cancer Institute

\section{Source}

National Cancer Institute. Macroscopic Findings Body System. NCI Thesaurus. Code C119854.

The body system or organ class associated with a macroscopic finding. 